\title{
Interventional Radiological Management of Hepatocellular Carcinoma
}

Hepatocellular carcinoma (HCC) is the sixth-most common cancer worldwide and the fourth-most common cause of death due to cancers. ${ }^{[1]}$ Its incidence is steadily increasing, and the common etiological factors include hepatitis $\mathrm{B}$ and $\mathrm{C}$, alcohol-induced chronic liver disease, and nonalcoholic fatty liver disease. ${ }^{[2,3]}$ Multiple staging systems have been proposed for classifying and guiding treatment decisions based on various factors which include tumor burden, background liver function, and performance status of the patients. The Barcelona Clinic Liver Cancer (BCLC) system [Figure 1] is the most widely accepted and followed worldwide. ${ }^{[4,5]}$ However, certain authors have suggested that BCLC is too conservative in treatment recommendations and thus have advocated the usage of the Hong Kong Liver Cancer system [Figure 2]. ${ }^{[6]}$

HCC recurrences are frequently seen in patients who have undergone curative treatments. ${ }^{[7]}$ Moreover, many patients in our country are no longer surgical candidates at the time of presentation. ${ }^{[8]}$ Hence, a multidisciplinary approach is required for the management of HCC. With the development and emergence of interventional radiological (IR) treatments, the management of $\mathrm{HCC}$ has changed dramatically. ${ }^{[9,10]}$ IR treatments are curative in patients with early-stage disease, while they play a major role in controlling disease, improving the quality of life, and improving survival in patients with advanced stages. ${ }^{[10,11]}$

The following IR treatment options are available for the treatment of HCC:

- Ablation techniques

- Chemical

- Thermal

- Electrical.

- Transarterial therapies

- Bland embolization

- Chemoembolization (Trans-arterial Chemoembolization [TACE]).

- Conventional

- Drug-Eluting Beads (DEB) based

- Radioembolization (transarterial radioembolization [TARE]).

- Other adjunct procedures such as portal vein embolization (PVE).

\section{Ablation Techniques}

Thermal ablation systems are indicated in early-stage patients when surgical options are precluded or the patient refuses for surgery. Ablation can replace resection in selected cases as it spares more liver parenchyma than anatomical resection. Thermal ablation systems have proven advantages and survival benefit over percutaneous ethanol injection (chemical ablation) and are currently established as the standard ablation method for local tumor control. ${ }^{[12]}$ Currently, most of the generated data are on radiofrequency ablation (RFA), which is the most commonly used ablative technique worldwide. It works on the principle of generating heat to kill the tumor cells using electrical current. Newer ablative techniques, such as microwave ablation (MWA), cryoablation, and irreversible electroporation, overcome some of the limitations of RFA. MWA produces higher intratumoral temperatures than RFA in a shorter duration of time and is capable of ablating larger tumors with less effect from adjacent vasculature. ${ }^{[13]}$ Early-stage HCC patients, with preserved liver functions (Child-Pugh Class A or B) with tumor size $<3 \mathrm{~cm}$, can be treated by RFA, and lesions up to $5 \mathrm{~cm}$ can be treated by MWA.

\section{Transarterial Therapies}

Transarterial therapies are suitable for unresectable and advanced-stage HCC, Child-Pugh class A or B. They can be combined with ablation/surgical resection or systemic therapy and act as a bridge to transplantation or help in downstaging before transplantation. ${ }^{[14,15]}$

Transarterial therapies can be performed in the following ways:

- Bland embolization performed with only embolic agents

- Chemoembolization (TACE) is the standard of care for patients with intermediate-stage HCC and relatively preserved liver functions. ${ }^{[16,17]}$ It is performed with chemotherapeutic agents mixed along with embolic agents. It can be performed as follows:

- cTACE (Conventional TACE) - ethiodized oil mixed with chemotherapeutic agents (doxorubicin or cisplatin)

- DEB-TACE - DEBs mixed with chemotherapeutic agents.

There is still debate as to which one of the above is better, and both methods show similar clinical outcomes. ${ }^{[18]}$ However, DEB-TACE has lesser drug-related adverse events and liver toxicity. ${ }^{[18]}$ The dose of doxorubicin typically ranges from $30 \mathrm{mg}$ to $75 \mathrm{mg}$ mixed with 5-15 $\mathrm{cc}$ of lipiodol in cTACE; however, up to $150 \mathrm{mg}$ of doxorubicin can be injected when combined with DEB-TACE for larger tumors. ${ }^{[19,20]}$ It is generally a well-tolerated procedure, and patients might experience postembolization syndrome which includes nausea/vomiting, fever, and abdominal pain. Acute hepatic decompensation is a rarer event and can be prevented by appropriate patient selection and performing technique. Although there are no defined number of TACE treatments 


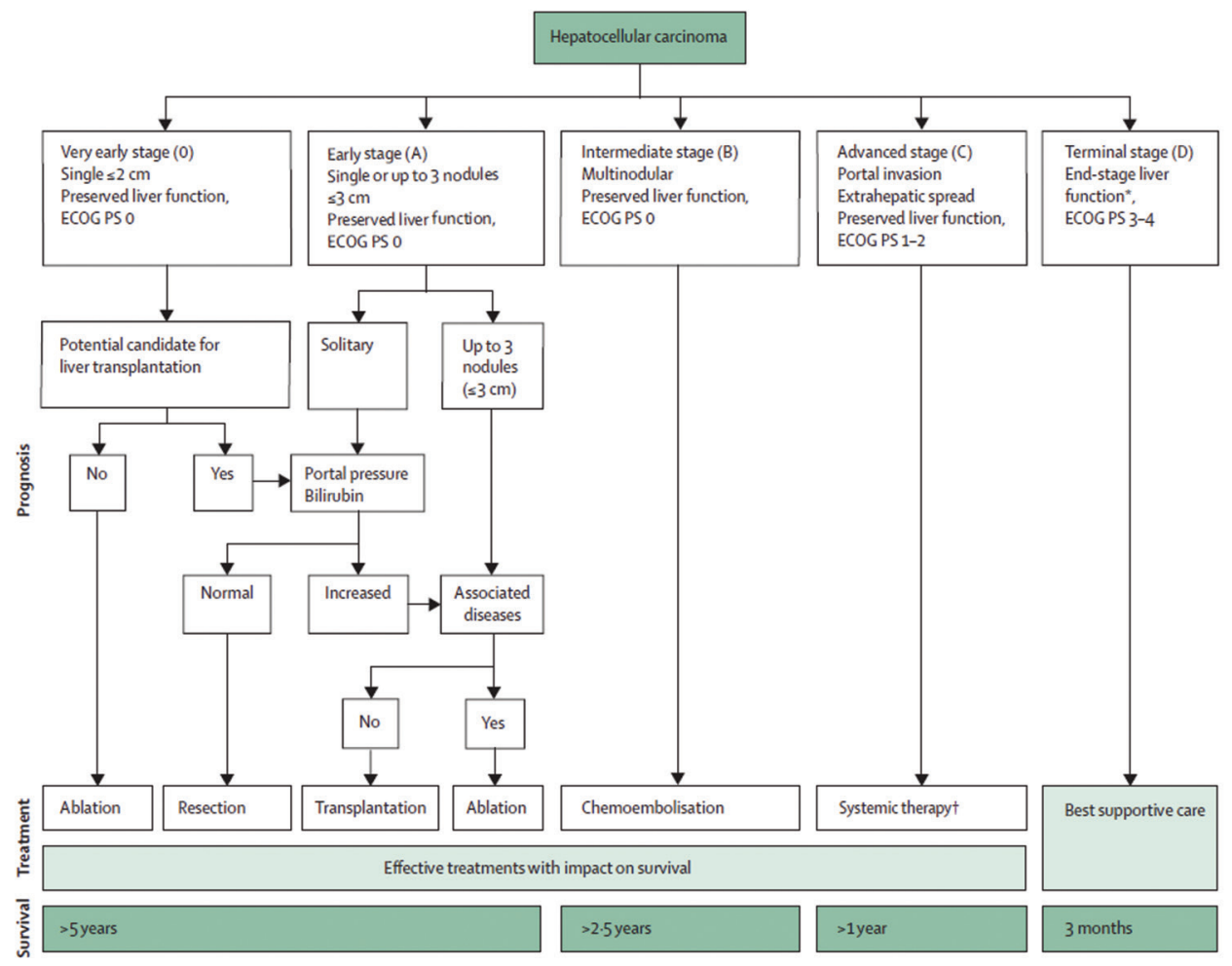

Figure 1: Barcelona clinic liver cancer staging system

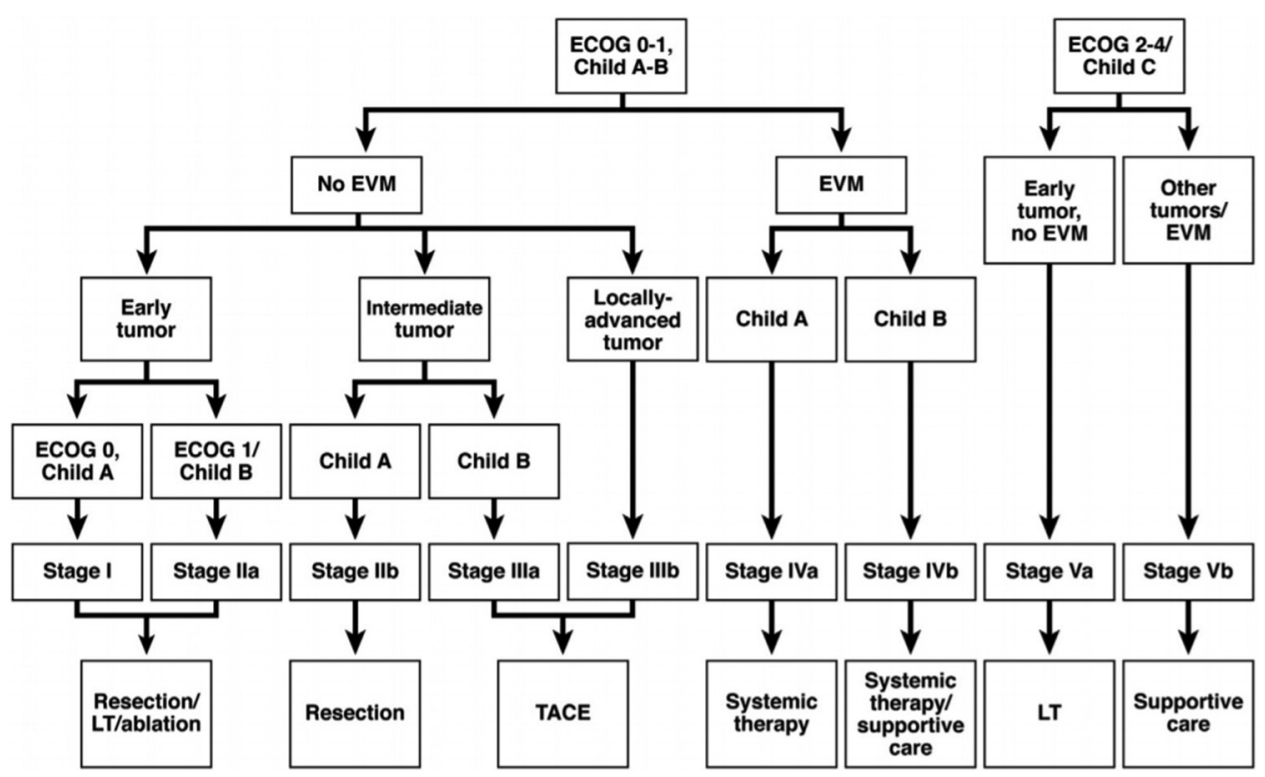

Figure 2: Hong Kong liver cancer classification

and consensus regarding retreatment schedule, TACE can be repeated after ascertaining the radiologic response and patient's tolerance. Superselective TACE can be performed for patients with portal vein branch thrombus and is not an absolute contraindication. ${ }^{[21]}$ The absolute contraindications of TACE include decompensated advanced cirrhosis, extensive tumor with massive replacement of both entire lobes, and main portal vein thrombosis with a high risk of posttreatment failure. ${ }^{[22]}$
- Radioembolization (TARE) is performed with selective intra-arterial administration of microspheres loaded with a radioactive element, with yttrium-90 (Y-90) being the most commonly used. It does not exert any macro-embolic effect and hence can be used even for patients with advanced portal venous thrombosis. ${ }^{[23]}$ The aim is to deliver a tumoricidal dose of approximately 120 Gy to the tumor while preventing damage to the surrounding liver parenchyma. It is done as a two-staged 
procedure, whereby a planning macroaggregated albumin (MAA) scan is done initially by injecting $99 \mathrm{~m}$-Tc-labeled MAA. It is used to assess the lung shunt fraction and splanchnic shunting, based on which dose modifications can be made.

Newer modifications of TARE techniques include radiation segmentectomy and radiation lobectomy which have further expanded its clinical utility. Patients might experience a postradioembolization syndrome which is usually less as compared to TACE. The rarer adverse events including radiation-induced liver disease, radiation pneumonitis, and gastrointestinal ulcers can be avoided by meticulous planning on a MAA scan. There are limited data with respect to the comparison of radioembolization with sorafenib. A study by Gramenzi et al. showed similar survival data of both these treatments in cirrhotic patients with intermediate-advanced-stage HCC; however, downstaging allowing liver transplantation only occurred after radioembolization. ${ }^{[24]}$

\section{Portal Vein Embolization}

In PVE, selective blockage of hepatic portal venous supply is done so that contralateral lobe hypertrophy can be induced by directing the portal flow to the segments of the future liver remnant. The patient can then undergo a resection with reduced chances of a complicated postoperative course.

With the availability of the abovementioned IR treatment options across our country, HCC patients, now, have multiple options. Combinations of these IR treatment options with systemic therapy including sorafenib and other newer agents have shown encouraging data in terms of improved disease control and survival. ${ }^{[25]}$ However, a recent phase 3 trial (TACE 2) showed contradictory data with a lack of survival benefit when combining antiangiogenic drugs with TACE. ${ }^{[2]}$ A combination of TACE with radiotherapy has also been studied in HCC patients with portal vein tumor thrombus, and few studies have shown improved patient outcomes. ${ }^{[27,28]}$ Similarly, for larger and oligonodular $\mathrm{HCC}$, resection and liver transplant remain the curative options, and IR treatments can act as a bridge to these surgical options. Therefore, a multidisciplinary approach to the management of HCC that includes the IR treatment options would lead to better patient outcomes.

\section{Abhishek Bansal, Arvind K Chaturvedi}

Department of Radiology and Interventional Oncology, Rajiv Gandhi Cancer Institute and Research Centre, New Delhi, India

Address for correspondence: Dr. Abhishek Bansal, Department of Radiology and Interventional Oncology, Rajiv Gandhi Cancer Institute and Research Centre, New Delhi - 110 085, India. E-mail:abhishek_mamc@yahoo.co.in

Submitted: 18 -Dec-2019

Revised: 03-Apr-2020

Accepted: 02-Jul-2020

Published: 29-Aug-2020

\section{References}

1. Bray F, Ferlay J, Soerjomataram I, Siegel RL, Torre LA, Jemal A. Global cancer statistics 2018: GLOBOCAN estimates of incidence and mortality worldwide for 36 cancers in 185 countries. CA Cancer J Clin 2018;68:394-424.

2. Kulik L, El-Serag HB. Epidemiology and management of hepatocellular carcinoma. Gastroenterology 2019;156:477-910.

3. Dyson J, Jaques B, Chattopadyhay D, Lochan R, Graham J, Das D, et al. Hepatocellular cancer: The impact of obesity, type 2 diabetes and a multidisciplinary team. J Hepatol 2014;60:110-7.

4. Cillo U, Vitale A, Grigoletto F, Farinati F, Brolese A, Zanus G, et al. Prospective validation of the Barcelona clinic liver cancer staging system. J Hepatol 2006;44:723-31.

5. Marrero JA, Fontana RJ, Barrat A, Askari F, Conjeevaram HS, $\mathrm{Su} \mathrm{GL}$, et al. Prognosis of hepatocellular carcinoma: comparison of 7 staging systems in an American cohort. Hepatology 2005;41:707-16.

6. Cheung TT, Kwok PC, Chan S, Cheung CC, Lee AS, Lee V, et al. Hong Kong consensus statements for the management of unresectable hepatocellular carcinoma. Liver Cancer 2018;7:40-54.

7. Zhou Y, Sui C, Li B, Yin Z, Tan Y, Yang J, et al. Repeat hepatectomy for recurrent hepatocellular carcinoma: A local experience and a systematic review. World J Surg Oncol 2010;8:55.

8. Kumar R, Saraswat MK, Sharma BC, Sakhuja P, Sarin SK. Characteristics of hepatocellular carcinoma in India: A retrospective analysis of 191 cases. QJM 2008;101:479-85.

9. Shrimal A, Prasanth M, Kulkarni AV. Interventional radiological treatment of hepatocellular carcinoma: An update. Indian J Surg 2012;74:91-9.

10. Molla N, AlMenieir N, Simoneau E, Aljiffry M, Valenti D, Metrakos $\mathrm{P}$, et al. The role of interventional radiology in the management of hepatocellular carcinoma. Curr Oncol 2014;21:e480-92.

11. Daher S, Massarwa M, Benson AA, Khoury T. Current and future treatment of hepatocellular carcinoma: An updated comprehensive review. J Clin Transl Hepatol 2018;6:69-78.

12. Bouza C, López-Cuadrado T, Alcázar R, Saz-Parkinson Z, Amate JM. Meta-analysis of percutaneous radiofrequency ablation versus ethanol injection in hepatocellular carcinoma. BMC Gastroenterol 2009;9:31.

13. Lubner MG, Brace CL, Hinshaw JL, Lee FT Jr. Microwave tumor ablation: mechanism of action, clinical results, and devices. J Vasc Interv Radiol 2010;21:S192-203.

14. Hayashi PH, Ludkowski M, Forman LM, Osgood M, Johnson S, Kugelmas M, et al. Hepatic artery chemoembolization for hepatocellular carcinoma in patients listed for liver transplantation. Am J Transplant 2004;4:782-7.

15. Graziadei IW, Sandmueller H, Waldenberger P, Koenigsrainer A, Nachbaur K, Jaschke W, et al. Chemoembolization followed by liver transplantation for hepatocellular carcinoma impedes tumor progression while on the waiting list and leads to excellent outcome. Liver Transpl 2003;9:557-63.

16. Bruix J, Sherman M. American association for the study of liver diseases. Management of hepatocellular carcinoma: An update. Hepatology 2011;53:1020-2.

17. European Association for the Study of the Liver; European Organisation for Research and Treatment of Cancer. EASL-EORTC Clinical Practice Guidelines: Management of Hepatocellular Carcinoma. J Hepatol 2012;56:908-43.

18. Song JE, Kim DY. Conventional vs. drug-eluting beads 
transarterial chemoembolization for hepatocellular carcinoma. World J Hepatol 2017;9:808-14.

19. Lencioni R, Petruzzi P, Crocetti L. Chemoembolization of hepatocellular carcinoma. Semin Intervent Radiol 2013;30:3-11.

20. Lencioni R, de Baere $T$, Burrel M, Caridi JG, Lammer J, Malagari $\mathrm{K}$, et al. Transcatheter treatment of hepatocellular carcinoma with Doxorubicin-loaded DC Bead (DEBDOX): Technical recommendations. Cardiovasc Intervent Radiol 2012;35:980-5.

21. Silva JP, Berger NG, Tsai S, Christians KK, Clarke CN, Mogal $\mathrm{H}$, et al. Transarterial chemoembolization in hepatocellular carcinoma with portal vein tumor thrombosis: a systematic review and meta-analysis. HPB (Oxford) 2017;19:659-66.

22. Facciorusso A, Licinio R, Muscatiello N, Di Leo A, Barone M. Transarterial chemoembolization: Evidences from the literature and applications in hepatocellular carcinoma patients. World J Hepatol 2015;7:2009-19.

23. Sacco R, Conte C, Tumino E, Parisi G, Marceglia S, Metrangolo $\mathrm{S}$, et al. Transarterial radioembolization for hepatocellular carcinoma: A review. J Hepatocell Carcinoma 2016;3:25-9.

24. Gramenzi A, Golfieri R, Mosconi C, Cappelli A, Granito A, Cucchetti A, et al. Yttrium-90 radioembolization vs sorafenib for intermediate-locally advanced hepatocellular carcinoma: A cohort study with propensity score analysis. Liver Int 2015;35:1036-47.

25. Liapi E, Geschwind JF. Combination of local transcatheter arterial chemoembolization and systemic anti-angiogenic therapy for unresectable hepatocellular carcinoma. Liver Cancer 2012;1:201-15.

26. Meyer T, Fox R, Ma YT, Ross PJ, James MW, Sturgess R, et al. Sorafenib in combination with transarterial chemoembolisation in patients with unresectable hepatocellular carcinoma (TACE 2): A randomised placebo-controlled, double-blind, phase 3 trial. Lancet Gastroenterol Hepatol 2017;2:565-75.

27. Yoon SM, Lim YS, Won HJ, Kim JH, Kim KM, Lee HC, et al. Radiotherapy plus transarterial chemoembolization for hepatocellular carcinoma invading the portal vein: Long-term patient outcomes. Int J Radiat Oncol Biol Phys 2012;82:2004-11.

28. Tazawa J, Maeda M, Sakai Y, Yamane M, Ohbayashi H, Kakinuma $\mathrm{S}$, et al. Radiation therapy in combination with transcatheter arterial chemoembolization for hepatocellular carcinoma with extensive portal vein involvement. J Gastroenterol Hepatol 2001;16:660-5.

This is an open access journal, and articles are distributed under the terms of the Creative Commons Attribution-NonCommercial-ShareAlike 4.0 License, which allows others to remix, tweak, and build upon the work non-commercially, as long as appropriate credit is given and the new creations are licensed under the identical terms.

\begin{tabular}{|l|l|}
\hline \multicolumn{2}{|c|}{ Access this article online } \\
\hline Quick Response Code: & Website: \\
& www.ijmpo.org \\
\cline { 2 - 2 } & DOI: \\
\hline
\end{tabular}

How to cite this article: Bansal A, Chaturvedi AK. Interventional radiological management of hepatocellular carcinoma. Indian $\mathrm{J}$ Med Paediatr Oncol 2020;41:484-7. 